\title{
Coxiella burnetii exposure in northern sea otters Enhydra lutris kenyoni
}

\author{
Colleen Duncan ${ }^{1, *}$, Verena A. Gill ${ }^{2,3}$, Kristin Worman ${ }^{3}$, Kathy Burek-Huntington ${ }^{4}$, \\ Kristy L. Pabilonia ${ }^{1}$, Sam Johnson ${ }^{1}$, Kelly A. Fitzpatrick ${ }^{5}$, Christina Weller $^{1}$, \\ Gilbert J. Kersh ${ }^{5}$
}

${ }^{1}$ Department of Microbiology, Immunology and Pathology, Colorado State University, Diagnostic Medicine Center, 300 West Drake Avenue, Fort Collins, Colorado 80523, USA

${ }^{2}$ Bureau of Ocean Energy Management, 3801 Centerpoint Drive, Suite 500, Anchorage, Alaska 99503, USA

${ }^{3}$ US Fish \& Wildlife Service, Marine Mammals Management, 1011 E. Tudor Road, MS 341, Anchorage, Alaska 99503, USA

${ }^{4}$ Alaska Veterinary Pathology Services, 23834 The Clearing Dr., Eagle River, Alaska 99577, USA

${ }^{5}$ Centers for Disease Control and Prevention, Rickettsial Zoonoses Branch, Building 18, Room SSB 221, 1600 Clifton Rd. Atlanta, Georga 30333, USA

\begin{abstract}
Valvular endocarditis has been well described in northern sea otters Enhydra lutris kenyoni of Alaska and in many cases no cause has been identified. It is also one of the most common conditions observed in people with chronic Coxiella burnetii infection. Given the high levels of $C$. burnetii exposure in marine mammals distributed throughout the same geographic range as the northern sea otter, and the presence of valvular lesions seen in otters, the objective of this study was to determine the level of $C$. burnetii exposure in otters and investigate any association between exposure, infection and valvular disease in this species. Archived serum from 75 live captured, apparently healthy otters ( 25 from each of 3 stocks) and 30 dead otters were tested for $C$. burnetii antibodies by indirect florescent antibody assay (IFA). Archived bone marrow and heart valves were tested for $C$. burnetii DNA by real-time PCR (qPCR). Overall, the seroprevalence in live otters was $17 \%$, with significantly more exposed animals in the south central $(40 \%)$ stock relative to the southwest $(8 \%)$ and southeast $(4 \%)$. The seroprevalence of animals sampled post mortem was $27 \%$, although none of the bone marrow or heart valve samples were positive by qPCR. Results of this study failed to demonstrate a significant association between C. burnetii infection and valvular endocarditis in sea otters; however, the differing seroprevalence suggests that exposure opportunities vary geographically.
\end{abstract}

KEY WORDS: Northern sea otters · Enhydra lutris kenyoni $\cdot$ Coxiella burnetii

\section{INTRODUCTION}

Coxiella burnetii, a bacterial pathogen capable of infecting a wide range of wild and domestic terrestrial animal hosts (Arricau-Bouvery \& Rodolakis 2005), has been increasingly recognized in marine mammals of the North Pacific Ocean. Placental disease (Kersh et al. 2010) and high placental and seroprevalence have been reported in Pacific harbor seals Phoca vitulina, harbor porpoises Phocoena phocoena and Steller sea lions Eumetopias jubatus (SSL) of the Pacific Northwest (Kersh et al. 2012). In 
Alaska, approximately $75 \%$ of northern fur seal Callorhinus ursinus (NFS) placentas tested positive for C. burnetii by real-time PCR (qPCR) (Duncan et al. 2012, 2013) and there is a high seroprevalence in both the NFS and the sympatric SSL populations (Minor et al. 2013). Environmental contamination and the persistence of $C$. burnetii on pinniped rookeries has been proposed a potential source of bacteria for other species (Duncan et al. 2013); however, the level of exposure and disease in other species throughout the region is largely unknown.

As inhabitants of the nearshore ecosystem, northern sea otters Enhydra lutris kenyoni are good sentinels for both pathogens and contaminants in coastal regions (Miller et al. 2002, Bossart 2006). Three population stocks of sea otters have been identified in Alaska (Fig. 1): the southeast (SE), south central (SC) and southwest (SW) Alaska stocks (USFWS 2014). The SW Alaska stock is listed as 'Threatend' under the Endangered Species Act. In the 19th Century, sea otters were hunted by fur traders to near extinction across their range, and while harvest restrictions brought about by the 1911 International Fur Seal Treaty resulted in a population recovery, declines between 50 and $95 \%$ have again been noted in the SW stock since the mid1980s (Estes et al. 2005). Causes for the decline are not completely understood; killer whales have been implicated (Estes et al. 1998, Kuker \& BarrettLennard 2010) but there are likely multiple factors involved, including shark predation and disease (Goldstein et al. 2011). The leading infectious and

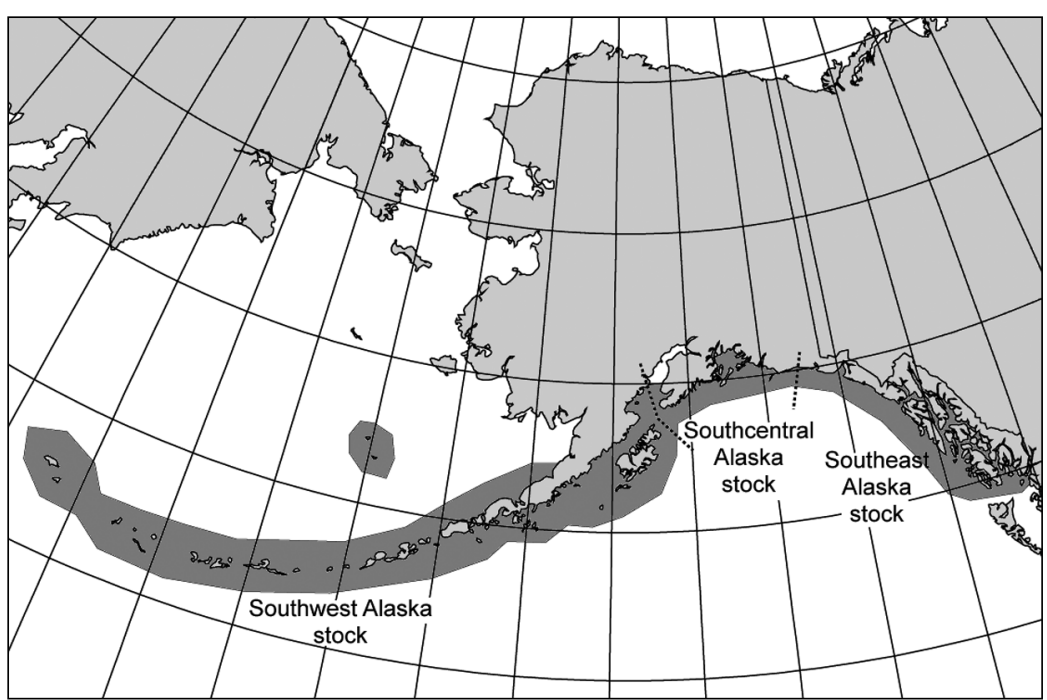

Fig. 1. Distribution of the northern (dark gray shading) sea otter Enhydra lutris kenyoni in Alaska showing approximate ranges of the 3 stocks non-infectious causes of death in Alaskan sea otters are septicemia of unknown origin and trauma, respectively (Counihan-Edgar et al. 2012, Carrasco et al. 2014).

Valvular endocarditis (VE) affects many species with a broad range of clinical presentations and causative agents. In sea otters, VE was first reported in 1990 when a male otter was collected in Prince William Sound, Alaska (SC stock) and transferred to Sea World in California where the otter became dyspneic and died of heart failure secondary to VE (Joseph et al. 1990). Since then, VE has been increasingly identified in northern sea otters in Alaska upon post mortem examination. Of 18 freshly dead animals necropsied between 2002 and 2005, 44\% had severe VE and thromboembolic disease (Burek et al. 2005). VE continues to be a common cause of mortality, and Streptococcus infantarius (a group D bacteria, formerly known as $S$. bovis) has been isolated from $42 \%(\mathrm{n}=144)$ of the fresh cases presented for necropsy (V. A. Gill unpubl. data).

In humans, VE associated with group D streptococcal isolates are found more commonly in older individuals with additional concurrent disease(s) and often heart valve replacements (Hoen et al. 2005), emphasizing the need to investigate similarly affected otters for evidence of comorbidity. In chronic human $C$. burnetii infection, VE is the most commonly identified lesion, and C. burnetii is the top differential for culture-negative VE as the bacteria does not grow using routine culture techniques (Maurin \& Raoult 1999, McQuiston \& Childs 2002, Houpikian \& Raoult 2005). Chronic infection and long term persistence of $C$. burnetii in bone marrow has been identified in humans many years after primary bacteremia (Harris et al. 2000); the significance of this finding is somewhat unclear, but may represent the source for bacteria during recrudescence (Marmion et al. 2005). Given the high prevalence of $C$. burnetii identified in marine mammals distributed throughout the same geographic range as the northern sea otter, and the presence of VE lesions in otters, the objective of this study was to determine the level of $C$. burnetii exposure in otters and investigate any association between exposure, infection, valvular disease and population changes in this species. 


\section{MATERIALS AND METHODS}

We utilized archived biological samples collected by, and under the authority of, the US Fish \& Wildlife Service (USFWS) (MMPA permit \# MA041309-1) as a part of ongoing health and disease assessments as well as fisheries conflict research. Animals were captured using surface-floating tangle nets set in nearshore waters in the vicinity of sea otters. Otters were anesthetized for morphometric studies and biological sample collection. Serum samples from apparently healthy animals collected in 2004 and 2005 (SW stock), 2007 (SC stock) and 2011 (SE stock) were frozen at $-80^{\circ} \mathrm{C}$ prior to use in the present study. Additional archived biological samples including formalin-fixed, paraffin-embedded and $-80^{\circ} \mathrm{C}$ frozen heart valves, bone marrow and serum were also available from animals examined post mortem as part of the USFWS stranding program between 2008 and 2012.

To determine the Coxiella burnetii seroprevalence in live, apparently healthy individuals, a total of 25 serum samples from each of the 3 stocks (43 male, 32 female) were randomly selected and tested for the presence of $C$. burnetii antibodies. To determine seroprevalence in dead otters, serology was conducted on 30 (20 male, 10 female) animals and was matched with a bone marrow sample and (when available) heart valve, which were tested by qPCR. The indirect immunofluorescensce assay (IFA) using antigens derived from both Nine Mile phase 1 and phase 2 strains was conducted at either the Centers for Disease Control and Prevention in Atlanta, Georgia or Colorado State University in Fort Collins, Colorado. The protocol was conducted as previously described (Kersh et al. 2012) using FITC-labeled goat anti-ferret (KPL) as a secondary antibody to detect binding. To prevent reporting of cross-reactive antibodies and false positives, the positive result cutoff was set at 1:128.

Bone marrow (collected from the femur) was available from 30 individuals with a matched serum sample as described above. A total of 26 frozen heart valves (20 control valves and 6 with gross or histologic evidence of $\mathrm{VE}$ ) were available for testing along with 37 formalin-fixed, paraffin-embedded heart valves (20 with histologic evidence of inflammation and 17 control valves). These tissues were tested for the presence of $C$. burnetii DNA by qPCR targeting the IS1111 insertion sequence and the com1 gene, as previously described (Kersh et al. 2010). DNA was extracted from frozen and formalin-fixed, paraffinembedded tissues using the QIAamp DNA Mini Kit
(Qiagen), according to the manufacturer's instructions for each sample type. A cycle threshold cutoff of 40.0 was used to identify a positive sample $\left(C_{\mathrm{T}} \leq 40\right)$.

\section{RESULTS}

Serology results are presented in Fig. 2. Of the 75 serum samples collected from live captured otters, antibody titers were identified in $13(17 \%)$ animals; 1 from the SE (4\%), 10 from the SC (40\%) and 2 from the SW stock $(8 \%)$. Of the positive animals, 3 had only phase 1 antibodies (1:128, 1:512, 1:1024), 4 had only phase 2 antibodies (all 1:128) and 6 had both phase 1 and phase 2 antibodies (4 at 1:256 phase 1, 2 at $\geq 1: 2048$ phase 1,4 at $1: 128$ phase 2,2 at $1: 256$ phase 2).

Of the 30 serum samples collected post mortem, cause of death was broadly classified based on post mortem examination findings as VE $(\mathrm{n}=8)$, trauma $(\mathrm{n}=8)$, sepsis $(\mathrm{n}=6)$, miscellaneous (intestinal torsion, neoplasia etc., $\mathrm{n}=5$ ) or unknown $(\mathrm{n}=3)$. In cases where aerobic bacterial culture was conducted $(\mathrm{n}=25)$, Streptococcus spp. was isolated from one or more tissues in $64 \%$ of the cases, suggesting that many animals were bacteremic at the time of death. Coxiella burnetii antibodies were detected in 8 $(27 \%)$ of the post mortem samples: 3 VE cases, 1 septicemic animal, 3 miscellaneous death cases and 1 that died of unknown causes. None of the animals that died as a result of acute trauma had antibodies to C. burnetii. The majority of the positive animals were

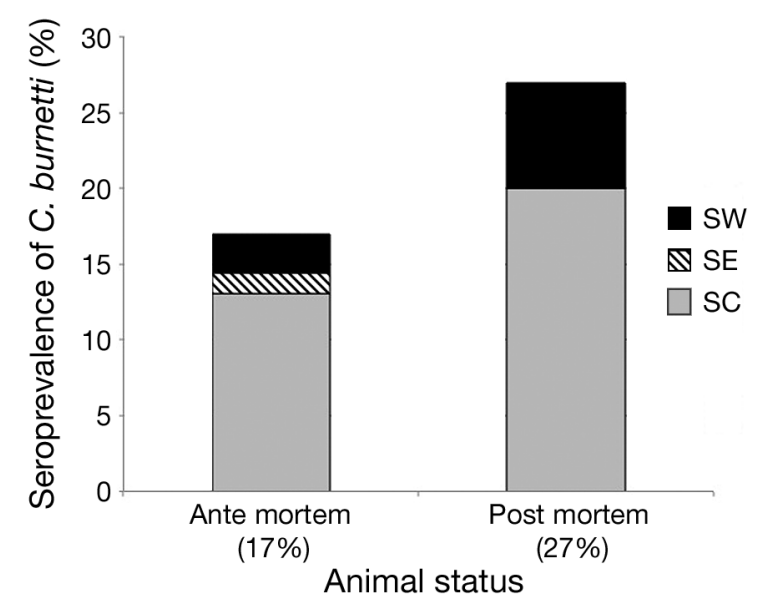

Fig. 2. Prevalence of Coxiella burnetii antibodies in serum collected both ante mortem $(n=75)$ and post mortem $(n=30)$ from the southwest (SW), southeast (SE) and south central (SC) stocks of northern sea otters Enhydra lutris kenyoni. No post-mortem samples from the SE stock were tested 
from the SC stock with an apparent prevalence of $25 \%$ (6 of 24), while the remaining 2 positive animals were from the SW stock (apparent prevalence $33 \%$ ). Antibodies were largely phase 1, with 6 animals having only phase 1 antibodies (2 at 1:128, 3 at 1:512 and 1 at 1:1024). A single animal had only phase 2 antibodies (1:256) and a single animal had titers to both phase 1 (1:1024) and phase 2 (1:256). All bone marrow $(\mathrm{n}=30)$ and heart valve tissues $(\mathrm{n}=73)$ were negative $\left(C_{\mathrm{T}}=0\right)$ on qPCR including the 8 animals that had antibody titers.

\section{DISCUSSION AND CONCLUSIONS}

Results of this study suggest that sea otters, as with other marine mammals in the North Pacific Ocean, have been exposed to Coxiella burnetii and have developed serum antibodies, but active infection is not common nor is the pathogen significantly associated with the observed VE syndrome. The apparent seroprevalence $(20 \%)$ in otters is significantly lower than that reported in NFSs (69\%) and SSLs (59\%) from an overlapping geographic range (Minor et al. 2013). Reasons for this discrepancy could be related to differing species susceptibilities, but is more likely due to differing exposure probabilities. Both NFSs and SSLs aggregate on rookeries to give birth and breed each season. C. burnetii localizes in the placenta and extremely high numbers of bacteria are shed with the birth products at parturition. As such, for species with high levels of infection and dense birthing grounds, there is a high likelihood for transmission during the pupping season. Additionally, because $C$. burnetii is persistent in the environment, repeated use of a particular birthing site results in a heavily contaminated area and a high probability of exposure. On St. Paul Island, Alaska, the marine mammal strain of $C$. burnetii can be identified yearround and is found exclusively in coastal areas associated with NFS rookeries (Duncan et al. 2013). In contrast to these pinnipeds, sea otters usually give birth in the water, separated from conspecifics (Riedman \& Estes 1990), and therefore disease transmission during parturition is minimized.

The seroprevalence of $C$. burnetii in live, apparently healthy sea otters from the SC stock was significantly higher (40\%) than both the SE (4\%) and SW $(8 \%)$ stocks. While VE has been diagnosed more frequently in the SC stock, it is also considerably easier to recover carcasses in this area, and therefore this association is likely biased (Carrasco et al. 2014). Given that all heart valve and bone marrow samples were negative for $C$. burnetii, there does not appear to be any relationship between infection with $C$. burnetii and VE in the sea otters of Alaska. In general, otters with antibodies tended to have higher and more frequent phase 1 versus phase 2 titers. In humans, elevated phase 1 titers are present in chronic infections while phase 2 titers are elevated during acute Q fever (Peacock et al. 1983). While nothing is known about the immune response of sea otters infected with $C$. burnetii, the higher and more common phase 1 titers in conjunction with the qPCR-negative tissues suggests that previous infection has been cleared. It is possible that repeated exposure of individual otters contributed to the elevated phase 1 titers in this species. Animals sampled post mortem were more likely to have $C$. burnetii antibodies, but the significance of this finding is difficult to interpret. Some of the serum samples collected post mortem exhibited signs of post mortem hemolysis compared to the high quality serum samples collected from live-caught otters, and it is possible that sample quality may have had an impact on IFA due to the increased viscosity of the samples. Alternatively, it is possible that otters dying of causes other than acute trauma were more likely to have been infected with C. burnetii and developed antibodies relative to live, apparently healthy individuals.

The differing seroprevalence between the 3 stocks likely represents differing exposure opportunities in the 3 areas. In humans, proximity to birthing areas of infected animals is a primary risk factor for C. burnetii infection (Schimmer et al. 2010). As sea otters spend most of their time in the nearshore habitat (Riedman \& Estes 1990) exposure opportunities may be increased if they spend more time adjacent to heavily infected pinniped rookeries. Unfortunately, nothing is known about the prevalence of placental infection or environmental C. burnetii contamination in these geographic areas. A better understanding of biological and ecological factors favoring persistence of $C$. burnetii in coastal environments would aid in the understanding of risks associated with human and animal occupancy of heavily colonized areas as well as the interpretation of antibody titers in localized populations.

While this study failed to identify $C$. burnetii as cause for VE in northern sea otters, it does provide novel information that is important for health assessment programs. Serosurveys conducted over time are a meaningful way to identify changing exposure opportunities, and integrating data on multiple infectious and non-infectious risk factors facilitates the identification of multifactorial problems. As C. bur- 
netii antibodies were less common in the declining SW population relative to the stable SC stock, exposure to this pathogen alone is insufficient to explain the failure of this stock to recover. Continued investigation into additional factors regulating northern sea otter recovery in the SW region is warranted.

Acknowledgements. This project was supported by funding from the North Pacific Research Board (publication no. 525). The findings and conclusions in this article are those of the authors(s) and do not necessarily represent the views of the US Fish \& Wildlife Service.

\section{LITERATURE CITED}

Arricau-Bouvery N, Rodolakis A (2005) Is Q fever an emerging or re-emerging zoonosis? Vet Res 36:327-349

Bossart G (2006) Marine mammals as sentinel species for oceans and human health. Oceanography 19:134-137

Burek KA, Bodkin JL, Doroff AM, Gill VA, Tuomi P, Miller MA, Jang SS (2005) Valvular endocarditis and septicemia due to Streptococcus infantarius ss coli organisms in stranded northern (Enhydra lutris kenyoni) and southern sea otters (Enhydra lutris nereis). In: Seward AK, Patterson R (eds) Proc Int Assoc Aquat Anim Med 36: 215-217

> Carrasco SE, Chomel BB, Gill VA, Kasten RW and others (2014) Novel Bartonella infection in northern and southern sea otters (Enhydra lutris kenyoni and Enhydra lutris nereis). Vet Microbiol 170:325-334

Counihan-Edgar KL, Gill VA, Doroff AM, Burek KA and others (2012) Genotypic characterization of Streptococcus infantarius subsp. coli isolates from sea otters with infective endocarditis and/or septicemia and from environmental mussel samples. J Clin Microbiol 50:4131-4133

Duncan C, Kersh GJ, Spraker T, Patyk KA, Fitzpatrick KA, Massung RF, Gelatt T (2012) Coxiella burnetii in northern fur seal (Callorhinus ursinus) placentas from St. Paul Island, Alaska. Vector Borne Zoonotic Dis 12:192-195

- Duncan C, Savage K, Williams M, Dickerson B and others (2013) Multiple strains of Coxiella burnetii are present in the environment of St. Paul Island, Alaska. Transbound Emerg Dis 60:345-350

Estes JA, Tinker MT, Williams TM, Doak DF (1998) Killer whale predation on sea otters linking oceanic and nearshore ecosystems. Science 282:473-476

Estes JA, Tinker MT, Doroff AM, Burn DM (2005) Continuing sea otter population declines in the Aleutian archipelago. Mar Mamm Sci 21:169-172

Goldstein T, Gill VA, Tuomi P, Monson D and others (2011) Assessment of clinical pathology and pathogen exposure in sea otters (Enhydra lutris) bordering the threatened population in Alaska. J Wildl Dis 47:579-592

Editorial responsibility: Michael Moore,

Woods Hole, Massachusetts, USA
Harris RJ, Storm PA, Lloyd A, Arens M, Marmion BP (2000) Long-term persistence of Coxiella burnetii in the host after primary Q fever. Epidemiol Infect 124:543-549

Hoen B, Chirouze C, Cabell CH, Selton-Suty C and others (2005) Emergence of endocarditis due to group D streptococci: findings derived from the merged database of the International Collaboration on Endocarditis. Eur J Clin Microbiol Infect Dis 24:12-16

> Houpikian P, Raoult D (2005) Blood culture-negative endocarditis in a reference center: etiologic diagnosis of 348 cases. Medicine 84:162-173

Joseph BE, Spraker TR, Migaki G (1990) Valvular endocarditis in a northern sea otter (Enhydra lutris). J Zoo Wildl Med 21:88-91

Kersh GJ, Lambourn DM, Self JS, Akmajian AM and others (2010) Coxiella burnetii infection of a Steller sea lion (Eumetopias jubatus) found in Washington State. J Clin Microbiol 48:3428-3431

Kersh GJ, Lambourn DM, Raverty SA, Fitzpatrick KA and others (2012) Coxiella burnetii infection of marine mammals in the Pacific Northwest, 1997-2010. J Wildl Dis 48: 201-206

Kuker K, Barrett-Lennard L (2010) A re-evaluation of the role of killer whales Orcinus orca in a population decline of sea otters Enhydra lutris in the Aleutian Islands and a review of alternative hypotheses. Mammal Rev 40: 103-124

> Marmion BP, Storm PA, Ayres JG, Semendric L and others (2005) Long-term persistence of Coxiella burnetii after acute primary Q fever. QJM 98:7-20

- Maurin M, Raoult D (1999) Q fever. Clin Microbiol Rev 12: 518-553

> McQuiston JH, Childs JE (2002) Q fever in humans and animals in the United States. Vector Borne Zoonotic Dis 2: 179-191

Miller MA, Gardner IA, Kreuder C, Paradies DM and others (2002) Coastal freshwater runoff is a risk factor for Toxoplasma gondii infection of southern sea otters (Enhydra lutris nereis). Int J Parasitol 32:997-1006

> Minor C, Kersh GJ, Gelatt T, Kondas AV and others (2013) Coxiella burnetii in northern fur seals and Steller sea lions of Alaska. J Wildl Dis 49:441-446

> Peacock MG, Philip RN, Williams JC, Faulkner RS (1983) Serological evaluation of $\mathrm{Q}$ fever in humans: enhanced phase I titers of immunoglobulins $\mathrm{G}$ and $\mathrm{A}$ are diagnostic for $Q$ fever endocarditis. Infect Immun 41:1089-1098

Riedman M, Estes J (1990) The sea otter (Enhydra lutris): behavior, ecology, and natural history. US Fish \& Wildlife Service Biological Report no. 90, Washington, DC

- Schimmer B, ter Schegget R, Wegdam M, Züchner L and others (2010) The use of a geographic information system to identify a dairy goat farm as the most likely source of an urban Q-fever outbreak. BMC Infect Dis 10:69

USFWS (2014) Sea otter stock assessment reports. www.fws. gov/alaska/fisheries/mmm/stock/stock.htm (accessed 4 Feb 2015)

Submitted: October 16, 2014; Accepted: February 2, 2015 Proofs received from author(s): April 11, 2015 